\title{
Photosynthetic responses of durum wheat to chemical/ microbiological fertilization management under salt and drought stresses
}

\author{
Mohammad Yaghoubi Khanghahi ${ }^{1} \cdot$ Beniamino Leoni $^{2} \cdot$ Carmine Crecchio $^{1}$ (i)
}

Received: 2 November 2020 / Revised: 11 June 2021 / Accepted: 10 July 2021 / Published online: 25 July 2021

(c) The Author(s) 2021

\begin{abstract}
The current research was carried out to evaluate the stress tolerance potential of durum wheat plants, in response to the inoculation of native plant growth-promoting bacteria (PGPB), through assessing PSII photochemistry and photosynthetic traits, as well as grain yield and plant height, and to investigate the possibility of using PGPB as a sustainable alternative or in combination with traditional fertilization plans. A greenhouse experiment included chemical/microbiological fertilization and stress (salinity and drought) treatments. The results indicated that the application of bacterial consortium of four PGPB markedly augmented some biochemical and functional traits in photosystem II, such as effective quantum yield of PSII photochemistry (Y(II)), electron transport rate of PSII (ETR), photosynthesis capacity, transpiration rate and stomatal conductance in unstressed plants, and prevented severe changes in the mentioned traits under drought and salinity conditions. The application of PGPB contributed to enhanced grain yield, too. Furthermore, a better performance of the PGPB inoculation was found in combination with half-dose of the recommended chemical fertilizers. In conclusion, PGPB inoculants maintain or improve the photosynthesis efficiency of durum wheat, grain yield and plant height, particularly under stress conditions, and can help to minimize the consumption of chemical fertilizers.
\end{abstract}

Keywords PGPB inoculants · Photosynthesis capacity $\cdot$ PSII photochemistry $\cdot$ Stomatal conductance $\cdot$ Transpiration rate

$\begin{array}{ll}\text { Abbreviations } \\ \text { BF } & \text { Seed treatment with commercial bio-fertilizer } \\ \text { CF } & \text { Soil treated with chemical fertilizers } \\ \text { Chl } a & \text { Chlorophyll } a \\ \text { ChlF } & \text { Chlorophyll florescence } \\ \text { Co } & \text { Control treatment (no fertilization) } \\ \text { DAS } & \text { Days after sowing } \\ \text { ETR } & \text { Electron transport rate } \\ F_{\mathrm{v}} / F_{\mathrm{m}} & \text { Maximum efficiency of PSII photochemistry in } \\ & \text { dark-adapted leaves } \\ \text { I } & \text { PGPB inoculation treatment } \\ \text { NPQ } & \text { Non-photochemical quenching }\end{array}$

Communicated by S. Srivastava.

Carmine Crecchio

carmine.crecchio@uniba.it

1 Department of Soil, Plant and Food Sciences, University of Bari Aldo Moro, Via Amendola 165/A, 70126 Bari, Italy

2 Department of Agricultural and Environmental Science, University of Bari Aldo Moro, Via Amendola 165/A, 70126 Bari, Italy
PGPB Plant growth-promoting bacteria

$\mathrm{qL} \quad$ Coefficient of photochemical fluorescence quenching assuming that all reaction centers share a common light-harvesting antenna

qN Non-photochemical quenching coefficient

$\mathrm{qP} \quad$ Photochemical quenching coefficient

$\mathrm{Y}(\mathrm{NO}) \quad$ Quantum yield of non-regulated energy loss in PSII

Y(NPQ) Quantum yield of light-induced NPQ

$\mathrm{Y}$ (II) Effective quantum yield of PSII photochemistry

\section{Introduction}

Durum wheat (Triticum durum Desf.) is one of the most widely grown cereals all over the Mediterranean region, where crops are continuously subjected to environmental stresses, particularly salinity and drought (Guidi and Calatayud 2014; Chairi et al. 2019), as the main environmental factors constrain crops productivity by affecting physiological processes (Nowicka et al. 2018). In fact, crop plants may activate the physiological and biochemical defense 
mechanisms to withstand these stresses for example altering their morphology and the photosynthesis response (Kamran et al. 2020). Since changes in photosystem activity are primary detrimental effects of abiotic stresses (Guidi and Calatayud 2014), evaluations of chlorophyll fluorescence (ChlF) and gas exchange, two powerful non-destructive and non-invasive techniques and indicators of photosynthetic energy conversion efficiency in crops, can be very useful to analyze the plant ecophysiological responses to stressful situations (Salvatori et al. 2014; Yaghoubian et al. 2016).

On the other hand, the average acquisition and accumulation of N, P, K and Zn by wheat plants are around 15-30, 3-5, 3-6 and $0.03-0.06 \mathrm{~kg}$ for each ton of grain yield, respectively (Prasad 2010; Paulsen et al. 2016; Duncan et al. 2018). Therefore, very large amounts of mineral fertilization inputs are generally used to provide crop plants with the essential nutrients, not only because of low availability of some nutrients in soil (e.g. N and P) for crop uptake (Bakhshandeh et al. 2015; Balasubramanian et al. 2015) but also of low solubility of some of them (e.g. $\mathrm{Zn}$ ) in soil that can be too slow to meet crop nutrient requirements (Rengel 2015). This issue is associated with the prices and availability of fertilizer inputs as the most important challenge facing today's farmers (Meena et al. 2017), especially in Italy, one of the Mediterranean countries and the secondworld producer of durum wheat with 4 million tons of grain in 2018 (ISTAT 2018).

Therefore, growing attention has arisen to find the environmentally friendly and cost-effective strategies, e.g. the utilization of plant growth-promoting bacteria (PGPB) inoculants to decrease the adverse impacts of stresses and the use of chemical inputs while reducing harmful effects on the food security and agro-ecosystem sustainability (Pii et al. 2016; Yaghoubi Khanghahi et al. 2018a). Several mechanisms of enhanced tolerance to stress, induced by these beneficial bacteria, have recognized, such as reinforcing the plant metabolism by releasing plant hormones and growth regulators (Meena et al. 2017; Kanagendran et al. 2019), stimulating plant defense mechanisms by promoting antioxidant activity and scavenging of reactive oxygen species (Kanagendran et al. 2019), biosynthesizing the 1-amino cyclopropane-1-carboxylate deaminase (ACC deaminase) which relieves the hypersensitive response upon ethyleneinduced stress (Chatterjee et al. 2018; Kanagendran et al. 2019), and increasing nutrient solubilization and biological nitrogen fixation (Pii et al. 2015). Unfortunately, relatively few studies have explored the photosynthesis responses of crop plants treated by the PGPB inoculations to stressful conditions. Therefore, the main objectives of this research were to investigate the possibility to use PGPB, as a sustainable alternative, or in combination with traditional fertilization plans, and to evaluate the stress tolerance potential of durum wheat plants in response to PGPB inoculations through assessing PSII photochemistry and photosynthetic traits. We hypothesized that the inoculation of native PGPB strains, previously isolated from a durum wheat field, is able to augment significantly, in comparison to traditional managements, the photosynthetic performance by changing the photosynthesis capacity, chlorophyll fluorescence parameters and gas exchanges, in plants grown in non-stress condition as well as in saline and drought stress.

\section{Materials and methods}

\section{Pot experiment}

A pot experiment was carried out in a completely randomized design with 3 replications; 105 pots were used in this experiment ( 7 fertilization levels $\times 5$ drought/saline stress levels $\times 3$ replications; fertilization and stress conditions are below described). Soil collection was done from the same durum wheat field from which the PGPB strains were isolated. The soil was clay loam with $0.99 \%$ organic C, $270 \mu \mathrm{g} \mathrm{C} \mathrm{g}^{-1}$ microbial biomass C, $10.4 \mathrm{C}: \mathrm{N}$ ratio, $31 \%$ water content at field capacity $(-0.3 \mathrm{Mpa}), 17 \%$ wilting point (-15 Mpa), $0.44 \mathrm{dS} \mathrm{m}^{-1}$ electrical conductivity of the soil saturation extract (EC), and $\mathrm{pH}$ 7.5. Plants were grown for 124 days in the greenhouse with a constant light/ temperature regime $\left(20^{\circ} \mathrm{C}, 14 \mathrm{~h}\right.$ light, and $10 \mathrm{~h}$ dark). Furthermore, pots were rotated weekly to avoid edge effects.

\section{Plant growth-promoting bacteria strains}

Four bacterial strains with potential plant-promoting traits, including Acinetobacter pittii (phosphate-solubilizing), Acinetobacter oleivorans (potassium-solubilizing), Acinetobacter calcoaceticus (zinc-solubilizing) and Comamonas testosteroni (nitrogen-fixing), previously isolated from a durum wheat field, were used as bio-inoculants. The isolation and identification of these bacterial strains, their solubilizing and fixation ability are fully described in Yaghoubi Khanghahi et al. (2020).

\section{Cross-streak test between co-inoculated strains}

A bacterial compatibility test was carried out before the use of a consortium of four PGPB strains. In this regard, each bacterial strain was cultivated in Nutrient Agar (NA) medium at $29^{\circ} \mathrm{C}$ for three days. After that, the second strain was streaked at an angle of approx. $90^{\circ}$ going outward from the emerged colonies of the first strain; the plate was incubated at $29{ }^{\circ} \mathrm{C}$ for other three days (Santiago et al. 2017). We considered its results as evidence of the compatibility of PGPB strains since neither inhibition zone nor antagonistic symptom was observed in plates. Finally, we used 
a consortium of the four PGPB bacteria for inoculation treatment.

\section{Preparation of PGPB inoculums and seed treatments}

The inocula were grown in Nutrient Broth (NB) medium, starting from a NA plate $24 \mathrm{~h}$ bacterial culture, under agitation at $100 \mathrm{rpm}$ for $24 \mathrm{~h}$ at $29{ }^{\circ} \mathrm{C}$. After centrifugation at $5000 \mathrm{rpm}$ for $5 \mathrm{~min}$, the pellets of the concentrated bacterial cultures were washed by a potassium chloride $0.9 \%$ $\mathrm{w} / \mathrm{v}$ sterile solution. The optical density of bacterial suspension at $600 \mathrm{~nm}$ was brought to $0.6-0.7$, showing a count of $10^{-6} \mathrm{CFU} \mathrm{ml}{ }^{-1}$.

Seeds (var. Furio Camillo) were surface-sterilized by shaking for $10 \mathrm{~min}$ in sodium hypochlorite solution (1\%) and washing several times with sterile water. Seeds and soil were inoculated with PGPB bacterial suspension (I treatment) before planting and every three weeks, respectively. Simultaneously to the PGPB treatment, commercial bio-fertilizer (BF, formulated by SIMCRO Crop Science, Italy) was used for seeds and soil inoculation. Seeds used for chemical fertilizers (CF) and control (Co) treatments were treated with potassium chloride $0.9 \% \mathrm{w} / \mathrm{v}$ sterile solution (Table 1). After germination of inoculated/treated seeds in each pot, six healthy seedlings were selected and kept until harvesting time.

\section{Chemical fertilization treatment}

Chemical fertilizers (CF) treatment was applied utilizing ammonium sulfate $\left(21 \% \mathrm{~N} ; 290 \mathrm{~kg} \mathrm{ha}^{-1}\right.$; divided into three parts and added before planting, at tillering and flowering stages), mono-ammonium phosphate $\left(52 \% \mathrm{P}_{2} \mathrm{O}_{5}\right.$ and $11 \% \mathrm{~N}$;

Table 1 Different levels of fertilization treatment including PGPB inoculation, chemical fertilizers and commercial bio-fertilizer

\begin{tabular}{llll}
\hline Biofertilizer & $\begin{array}{l}\text { PGPB inocula- } \\
\text { tion }\end{array}$ & $\begin{array}{l}\text { Chemical ferti- } \\
\text { lizer }\end{array}$ & Treatments \\
\hline- & - & - & $\mathrm{Co}$ \\
- & + & - & $\mathrm{I}$ \\
+ & - & - & $\mathrm{BF}$ \\
- & - & + & $\mathrm{CF}$ \\
- & + & + & $\mathrm{CF}+\mathrm{I}$ \\
- & - & + & $1 / 2 \mathrm{CF}$ \\
- & + & + & $1 / 2 \mathrm{CF}+\mathrm{I}$ \\
\hline
\end{tabular}

$I$ inoculation of seed using beneficial bacterial consortium. Pots were also inoculated by bacterial suspension every 3 weeks; $B F$ seed treatment with commercial bio-fertilizer. Pots were also treated every 3 weeks, simultaneously to the PGPB treatment; $C F$ adding chemical fertilizers to the soil; $1 / 2 C F$ half-dose of recommended chemical fertilizers; Co control treatment (no chemical and microbiological fertilizer) $\left.115 \mathrm{~kg} \mathrm{ha}^{-1}\right)$, potassium sulfate $\left(44 \% \mathrm{~K}_{2} \mathrm{O} ; 75 \mathrm{~kg} \mathrm{ha}^{-1}\right)$ and zinc oxide $\left(75 \% \mathrm{Zn} ; 10 \mathrm{~kg} \mathrm{ha}^{-1}\right)$.

\section{Drought/saline stress treatment}

Five levels of stress included a non-stress (control), two levels of drought at $40 \%$ and $60 \%$ of field capacity and two levels of salinity ( $75 \mathrm{mM} \mathrm{NaCl}$ and $150 \mathrm{mM} \mathrm{NaCl})$, which were applied at the booting stage (63 days after sowing, 63 DAS), when the head of the durum wheat plants developed and became visible beneath the sheath on the stalk. Plants were treated with the saltwater solution every three days (until $81 \mathrm{DAS}$ ) by dividing the solution volume into three parts and adding to the pots gradually every $2-3 \mathrm{~h}$, to avoid osmotic shock.

\section{Chlorophyll concentration and photosynthetic pigments}

Flag leaves of durum wheat plants were used for measuring from each treatment at 84 DAS. Leaf chlorophyll concentration and relative chlorophyll content (SPAD value) were measured by chlorophyll concentration meter (MC-100, Apogee instruments, USA) and portable chlorophyll meter (SPAD-502, Minolta, Japan), respectively. Fresh samples of flag leaves $\left(1.0 \mathrm{~cm}^{2}\right)$ were used to determine the chlorophyll $a(\mathrm{Chl} a), b(\mathrm{Chl} b)$ and carotenoids content according to the Porra (2002) method. Briefly, samples were incubated in methanol at room temperature for $24 \mathrm{~h}$ in darkness. Then, the absorption at visible wavelengths of $665.2\left(A_{665.2}\right), 652.4$ $\left(A_{652.4}\right)$ and $470\left(A_{470}\right) \mathrm{nm}$ was determined using a spectrophotometer (Ultrospec 4000, Pharmacia Biotech Inc. USA). The following equations were used to calculate the Chla, $\mathrm{Chl} b$ and carotenoid content (Yaghoubian et al. 2016):

$$
\begin{aligned}
& \text { Chl } a\left(\mu \mathrm{g} \mathrm{cm}^{-2}\right)=16.72 A_{665.2}-9.16 A_{652.4} \\
& \operatorname{Chl} b\left(\mu \mathrm{g} \mathrm{cm}^{-2}\right)=34.09 A_{652.4}-15.28 A_{665.2} \\
& \text { Carotenoid }\left(\mu \mathrm{g} \mathrm{cm}^{-2}\right) \\
& =\left(1000 A_{470}-1.63 \mathrm{Chl} a-104.96 \mathrm{Chl} b\right) / 221
\end{aligned}
$$

\section{Gas exchange and chlorophyll fluorescence parameters}

The LI-COR portable photosynthesis system (LI-COR 6400/ XT, USA) was used to estimate the stomatal conductance, transpiration and photosynthesis rate of the flag leaves at 89 DAS between 11 am and $1 \mathrm{pm}$. ChlF parameters were estimated from the flag leaves at 92 DAS using a Pulse 

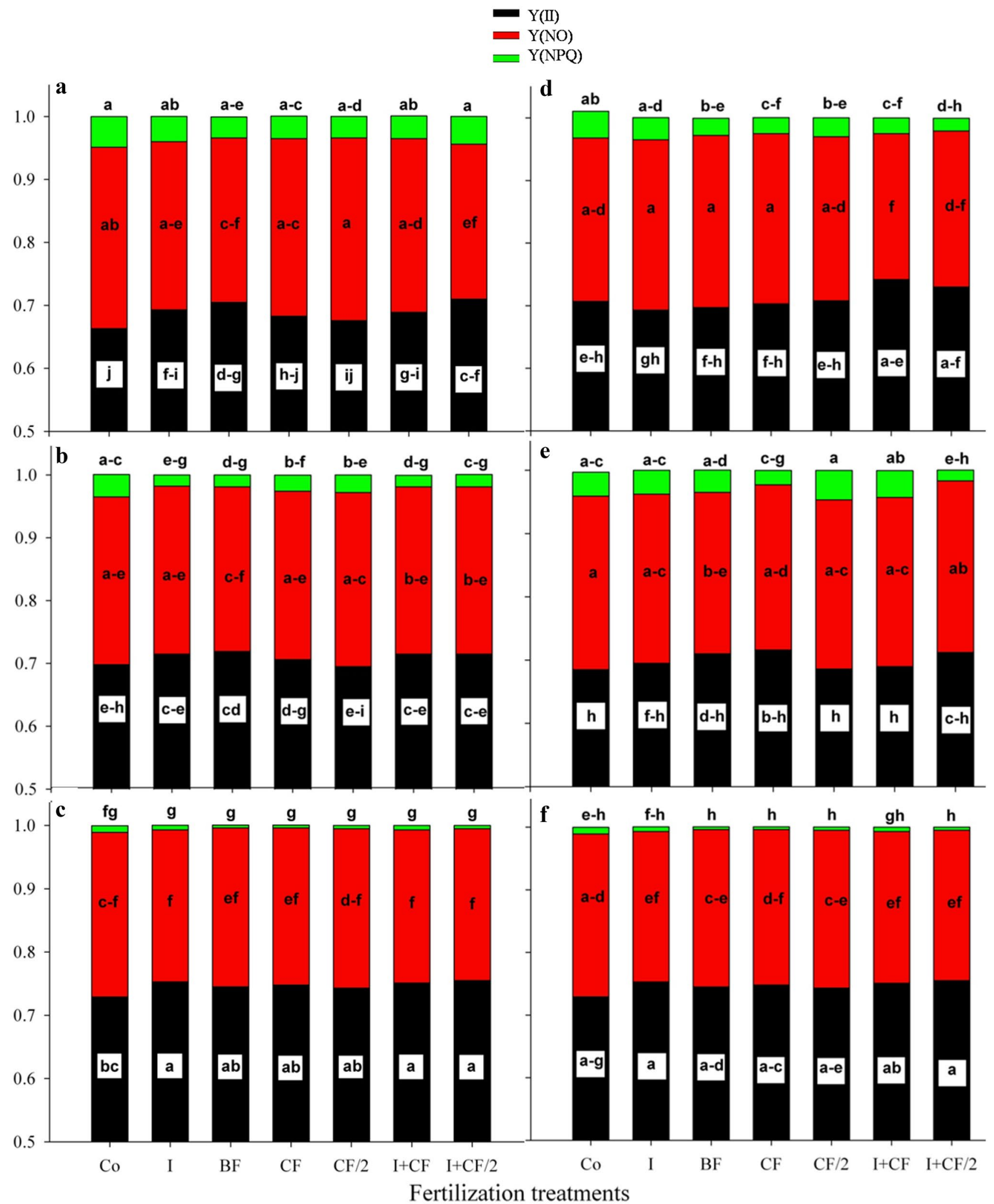

Amplitude Modulated fluorometer (PAM-2500, Walz, Germany), as described by Genty et al. (1989). Dark leaf clips (DLC-8) were used to acclimate the leaves to dark for $15 \mathrm{~min}$ before the measurements and consequently the basal fluorescence $\left(F_{0}\right)$ and the maximum fluorescence $\left(F_{\mathrm{m}}\right)$ level were measured without interference of ambient 
४Fig. 1 Effective quantum efficiency of PSII (Y(II)), quantum yield of light-induced non-photochemical quenching (Y(NPQ)) and quantum yield of non-regulated energy dissipation (Y(NO)) as affected by fertilization treatments in severe, mild and control levels of drought $(\mathbf{a}, \mathbf{b}$ and $\mathbf{c}$ ) and salinity (d, e and $\mathbf{f}$ ), respectively. $I$ inoculation of seed using beneficial bacterial consortium. Pots were also inoculated by bacterial suspension every 3 weeks; $B F$ seed treatment with commercial bio-fertilizer. Pots were also treated every 3 weeks, simultaneously to the PGPB treatment; $C F$ adding full dose of recommended chemical fertilizers to the soil; $C F / 2$ half-dose of recommended chemical fertilizers; Co control treatment (no chemical and microbiological fertilizer)

light. Accordingly, the leaf was exposed to low intensity light $\left(<0.1 \mu \mathrm{mol}\right.$ photons $\mathrm{m}^{-2} \mathrm{~s}^{-1}$, red light). Afterwards, a saturating light pulse $\left(>8000 \mu \mathrm{mol}\right.$ photons $\mathrm{m}^{-2} \mathrm{~s}^{-1}$, white light) was turned on for $1 \mathrm{~s}$ (one pulse). The maximum quantum yield of PSII was estimated on dark-adapted leaves as $F_{\mathrm{v}} / F_{\mathrm{m}}=\left[\left(F_{\mathrm{m}}-F_{0}\right) / F_{\mathrm{m}}\right]$ where $F_{\mathrm{v}}$ is the variable fluorescence. The effective quantum efficiency $\Phi_{\mathrm{PSII}}$ was evaluated as $\left(F_{\mathrm{m}}{ }^{\prime}-F\right) / F_{\mathrm{m}}{ }^{\prime}$, where $F$ is the steady-state fluorescence and $F_{\mathrm{m}}{ }^{\prime}$ is the maximum fluorescence measured in light-exposed leaf samples. Other estimated parameters included the photosynthetic electron transport rate (ETR, $\mu \mathrm{mol}$ electrons $\left.\mathrm{m}^{-2} \mathrm{~s}^{-1}\right)$, the quantum yield of light-induced non-photochemical quenching $\left[\mathrm{Y}(\mathrm{NPQ})=\left(F / F_{\mathrm{m}}{ }^{\prime}\right)-\left(F / F_{\mathrm{m}}\right)\right]$, the quantum yield of non-regulated energy dissipation $\left[\mathrm{Y}(\mathrm{NO})=F / F_{\mathrm{m}}\right]$, the non-photochemical quenching $\left[\mathrm{NPQ}=\left(F_{\mathrm{m}}-F_{\mathrm{m}}{ }^{\prime}\right) / F_{\mathrm{m}}{ }^{\prime}\right]$, the coefficient of non-photochemical fluorescence quenching $\left[\mathrm{qN}=1-\left(F_{\mathrm{m}}{ }^{\prime}-F_{0}\right) /\left(F_{\mathrm{m}}-F_{0}\right)\right]$, the coefficient of photochemical fluorescence quenching based on a model of separate photosynthetic units $\left[\mathrm{qP}=\left(F_{\mathrm{m}}{ }^{\prime}-F\right) /\left(F_{\mathrm{m}}{ }^{\prime}-F_{0}{ }^{\prime}\right)\right]$ and coefficient of photochemical fluorescence quenching assuming that all reaction centers share a common light-harvesting antenna $\left[\mathrm{qL}=\mathrm{qP} \times\left(F_{0}{ }^{\prime} / F\right)\right]$ (Bilger and Björkman 1990 .

All six durum wheat plants from each pot were harvested at 124 DAS and then the grain yield per plant and plant height were determined. All statistical analyses including a two-way analysis of variance (ANOVA), the least significant difference (LSD) test and multiple linear regression (backward method), as well as drawing the graphs, were performed using the SigmaPlot software.

\section{Results}

Our findings in non-stress conditions showed that all fertilizer levels improved the concentration of photosynthesis pigments and chlorophyll concentration as compared to the unfertilized treatment. In particular, Chl $a$, Chl $b$ and carotenoids contents, SPAD value and chlorophyll concentration (determined by MC-100 chlorophyll concentration meter) in PGPB-inoculated pots were 8.8, 41, 4.5, 6.9 and $10.5 \%$ higher than those in unfertilized pots, respectively. When PGPBs were combined to half-dose of chemical fertilizer
$(\mathrm{I}+1 / 2 \mathrm{CF})$, these increments were $30.4,10.8,40.5,9.6$ and $25.5 \%$, respectively (Table S1). The highest amounts of chlorophyll and SPAD values were obtained from combined treatment of bacterial inoculants and a full dosage of chemicals (I $+\mathrm{CF}$ treatment) under non-stress condition, equal to $561.3 \mu \mathrm{mol} \mathrm{m}{ }^{-2}$ and 53.5, which were 45 and $21 \%$ higher than those in unfertilized plants, 31 and $14 \%$ more than PGPB-inoculated plants, and 24 and $10 \%$ higher that plants treated by chemical fertilizers (Table $\mathrm{S} 1$ ). Chl $b$ and carotenoids contents were almost higher under the mild stress than control and severe levels, for both drought and salinity conditions, with a few exceptions. Accordingly, $\mathrm{Chl} b$ and carotenoid reached the maximum value in PGPB inoculation (I) and I + CF treatments, respectively (Table S1).

All the considered ChlF parameters were influenced by fertilization treatments that also induced Y(NPQ) and qN to decrease in comparison to the unfertilized treatment, in both unstressed and stressed plants, except for mild salinity level. The values varied from 0.004 to 0.049 and 0.047 for Y(NPQ) (Fig. 1), and from 0.022 and 0.025 to 0.188 and 0.190 for $\mathrm{qN}$ in the drought and salinity, respectively (Table S2). Similarly, Y(NO) slightly (3-7\%; Fig. 1) and NPQ intensely (24-56\%; Table S2) decreased by fertilization treatments in comparison to the unfertilized treatment in unstressed plants. Unlike non-stress conditions, no specific response to the fertilization and stress treatments appeared in these parameters. Nevertheless, their amount increased at all levels of fertilization treatment under the stress as compared to the same fertilization level in non-stress. For example, NPQ in drought and salinity were 2.3 and 5 times higher than non-stress as affected by inoculation treatment (I). In opposite, qP slightly increased by applying the fertilization treatments in both non-stress and stress conditions. The highest values of $\mathrm{qL}$ were obtained from the CF (0.94) and $\mathrm{BF}(0.92)$ treatments under the mild level of drought and salinity, respectively, while the minima were 0.69 and 0.74 (Co treatment) under the severe drought and control level of salinity (Table S2).

No statistically significant difference was observed between treatments in terms of $F_{\mathrm{v}} / F_{\mathrm{m}}$ in both stress conditions. However, this parameter decreased under stress condition and increased by fertilization treatments as compared to the control. The ratio of $F_{\mathrm{v}} / F_{\mathrm{m}}$ varied from 0.75 and 0.76 to 0.80 in the drought and salinity, respectively (Table S2). A similar trend was observed for Y(II) in both stresses. Almost all the fertilization treatments, especially the application of PGPB inoculants alone or combined with the chemical fertilizers, significantly increased the Y(II) values in comparison to the unfertilized treatment in both unstressed and stressed plants In case of drought, this parameter reached the highest value for $\mathrm{I}+1 / 2 \mathrm{CF}$ treatment, equal to $0.755,0.715$ and 0.710 in the non-stress, mild and severe stress levels, which were 3.5, 2.7 and $7.1 \%$ higher than that in unfertilized plants, 1 , 
1.3 and $4 \%$ more than CF treatment, and $0.3,0$ and $2.5 \%$ higher than I treatment at the same stress levels, respectively. Also, the highest $\mathrm{Y}(\mathrm{II})$ values in the non-stress, mild and severe levels of salinity were detected in $\mathrm{I}+1 / 2 \mathrm{CF}, \mathrm{CF}$ and $\mathrm{I}+\mathrm{CF}$ which were $3.5,4.8$ and $5 \%$ more than that in the unfertilized plants at the same salinity levels, respectively (Fig. 1).

Photosynthetic capacity and transpiration rate in the drought stress were significantly higher in plants grown under the fertilization treatments, especially in the control and mild levels of stress. PGPB inoculations (I treatment) significantly increased the photosynthetic capacity and transpiration rate as compared to the unfertilized plants (19 and $41 \%$, respectively) under non-stress condition, which were non-significantly lower than CF treatment (2.4 and 3.8\%, respectively). This increment by the I treatment was not significant in other levels of drought; however, the values were higher than the unfertilized plants, equal to 4.2 and $27.7 \%$ in the mild and 8.9 and $24.5 \%$ in the severe drought. Nevertheless, there were no statistically significant differences between PGPB inoculations treatment and $\mathrm{CF}, \mathrm{I}+\mathrm{CF}$ and $\mathrm{I}+1 / 2 \mathrm{CF}$ treatments. However, the strongest photosynthetic capacity at the mild salinity level was observed in the $\mathrm{CF}$ treatment, but PGPB-inoculated plants had higher photosynthetic capacity under the severe salinity, which was $14.8 \%$ more than that in unfertilized plants at the same salinity level (Fig. 2).

The maximum electron transport rate (ETR) of PSII in non-stress conditions belonged to the $\mathrm{I}$ and $\mathrm{I}+1 / 2 \mathrm{CF}$ treatments, which were slightly more than the $\mathrm{CF}$ and $\mathrm{BF}$ treatments (Table 2). ETR values varied from 0.278 and 0.288 to $0.317 \mu \mathrm{mol}$ electrons $\mathrm{m}^{-2} \mathrm{~s}^{-1}$ in the drought and salinity, respectively. Almost the same trend was observed at other levels of drought stress, except for BF treatment. In this regard, the highest ETR value was obtained from $\mathrm{CF}$ treatment at the mild level of salinity, while only I $+\mathrm{CF}$ and $\mathrm{I}+1 / 2 \mathrm{CF}$ treatments were able to improve this parameter at the severe level of salinity (Table 2).

All fertilizer treatments, especially the PGPB inoculations, improved the stomatal conductance as compared to
Fig. 2 Photosynthesis capacity and transpiration rate in response to the chemical/ microbiological fertilization managements under drought (a) and salt (b) stresses. $I$ inoculation of seed using beneficial bacterial consortium. Pots were also inoculated by bacterial suspension every 3 weeks; $B F$ seed treatment with commercial biofertilizer. Pots were also treated every 3 weeks, simultaneously to the PGPB treatment; $C F$ adding full dose of recommended chemical fertilizers to the soil; $C F / 2$ half-dose of recommended chemical fertilizers; $C o$ control treatment (no chemical and microbiological fertilizer)
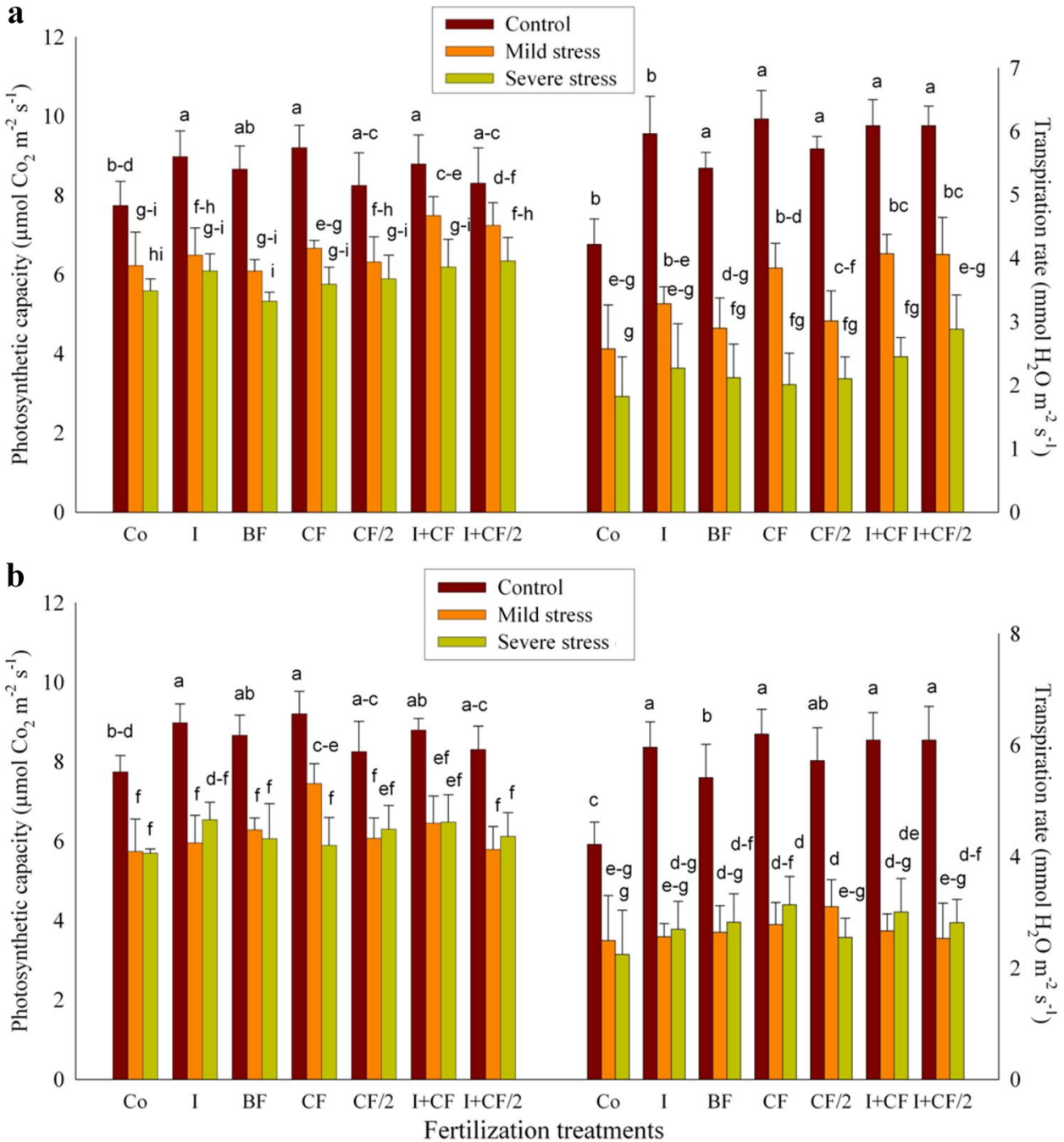
Table 2 Estimation of stomatal conductance and electron transport rate (ETR) as affected by fertilization and stress treatments, as well as their increment rates in comparison to the unfertilized treatment in each stress level

\begin{tabular}{|c|c|c|c|c|c|c|c|c|c|}
\hline \multirow[t]{3}{*}{ Stress } & \multirow[t]{3}{*}{ Fertilizer } & \multicolumn{4}{|l|}{ Drought } & \multicolumn{4}{|l|}{ Salinity } \\
\hline & & $\begin{array}{l}\text { Stomatal } \\
\text { conductance }\end{array}$ & $\begin{array}{l}\text { Increment } \\
\text { rate }\end{array}$ & ETR & $\begin{array}{l}\text { Increment } \\
\text { rate }\end{array}$ & $\begin{array}{l}\text { Stomatal } \\
\text { conductance }\end{array}$ & $\begin{array}{l}\text { Increment } \\
\text { rate }\end{array}$ & ETR & Increment rate \\
\hline & & $\begin{array}{l}\text { mmol } \\
\mathrm{m}^{-2} \mathrm{~s}^{-1}\end{array}$ & $\%$ & $\begin{array}{l}\mu \mathrm{mol} \\
\mathrm{m}^{-2} \mathrm{~s}^{-1}\end{array}$ & $\%$ & $\begin{array}{l}\mathrm{mmol} \\
\mathrm{m}^{-2} \mathrm{~s}^{-1}\end{array}$ & $\%$ & $\begin{array}{l}\mu \mathrm{mol} \\
\mathrm{m}^{-2} \mathrm{~s}^{-1}\end{array}$ & $\%$ \\
\hline \multirow[t]{7}{*}{ Control } & $\mathrm{Co}$ & $0.09 \mathrm{~cd}$ & - & $0.31 \mathrm{a}-\mathrm{f}$ & - & $0.09 \mathrm{~cd}$ & - & $0.31 \mathrm{a}-\mathrm{g}$ & - \\
\hline & I & $0.15 \mathrm{ab}$ & 53.5 & $0.32 \mathrm{ab}$ & 3.3 & $0.15 \mathrm{ab}$ & 53.5 & $0.32 \mathrm{a}$ & 3.3 \\
\hline & $\mathrm{BF}$ & $0.12 \mathrm{bc}$ & 24.9 & $0.31 \mathrm{a}-\mathrm{d}$ & 2.3 & $0.12 b c$ & 24.9 & $0.31 \mathrm{a}-\mathrm{c}$ & 2.3 \\
\hline & $\mathrm{CF}$ & $0.16 \mathrm{a}$ & 70.4 & $0.31 \mathrm{a}-\mathrm{c}$ & 2.6 & $0.16 \mathrm{ab}$ & 70.4 & $0.31 \mathrm{ab}$ & 2.6 \\
\hline & $1 / 2 \mathrm{CF}$ & $0.12 b c$ & 30.2 & $0.31 \mathrm{a}-\mathrm{e}$ & 2.0 & $0.12 b c$ & 30.2 & $0.31 \mathrm{a}-\mathrm{d}$ & 2.0 \\
\hline & $\mathrm{I}+\mathrm{CF}$ & $0.17 \mathrm{a}$ & 77.8 & $0.32 \mathrm{ab}$ & 2.9 & $0.17 \mathrm{ab}$ & 77.8 & $0.32 \mathrm{ab}$ & 2.9 \\
\hline & $\mathrm{I}+1 / 2 \mathrm{CF}$ & $0.14 \mathrm{ab}$ & 50.3 & $0.32 \mathrm{a}$ & 3.6 & $0.14 \mathrm{ab}$ & 50.3 & $0.32 \mathrm{a}$ & 3.6 \\
\hline \multirow[t]{7}{*}{ Mild stress } & $\mathrm{Co}$ & $0.03 \mathrm{f}$ & - & $0.29 \mathrm{f}-\mathrm{i}$ & - & $0.05 \mathrm{ef}$ & - & $0.29 \mathrm{~h}$ & - \\
\hline & I & $0.08 \mathrm{de}$ & 167.8 & $0.30 \mathrm{~b}-\mathrm{g}$ & 2.4 & 0.04 ef & -9.1 & $0.29 \mathrm{gh}$ & 1.4 \\
\hline & $\mathrm{BF}$ & $0.04 \mathrm{f}$ & 40.6 & $0.30 \mathrm{a}-\mathrm{g}$ & 3.1 & 0.04 ef & -20.9 & $0.30 \mathrm{c}-\mathrm{h}$ & 3.5 \\
\hline & $\mathrm{CF}$ & $0.06 \mathrm{~d}-\mathrm{f}$ & 113.1 & $0.30 \mathrm{~d}-\mathrm{h}$ & 1.4 & $0.07 \mathrm{de}$ & 53.2 & $0.30 \mathrm{~b}-\mathrm{h}$ & 4.5 \\
\hline & $1 / 2 \mathrm{CF}$ & $0.06 \mathrm{~d}-\mathrm{f}$ & 105.4 & $0.29 \mathrm{f}-\mathrm{i}$ & -0.34 & $0.06 \mathrm{~d}-\mathrm{f}$ & 41.8 & $0.29 \mathrm{~h}$ & 0 \\
\hline & $\mathrm{I}+\mathrm{CF}$ & $0.09 \mathrm{~cd}$ & 204.4 & $0.30 \mathrm{~b}-\mathrm{g}$ & 2.4 & 0.04 ef & -1.5 & $0.29 \mathrm{~h}$ & 0.7 \\
\hline & $\mathrm{I}+1 / 2 \mathrm{CF}$ & $0.10 \mathrm{~cd}$ & 222.5 & $0.30 \mathrm{~b}-\mathrm{g}$ & 2.4 & 0.03 ef & -32.4 & $0.30 \mathrm{c}-\mathrm{h}$ & 3.8 \\
\hline \multirow[t]{7}{*}{ Severe stress } & Co & $0.03 \mathrm{f}$ & - & $0.28 \mathrm{i}$ & - & $0.03 \mathrm{f}$ & - & $0.29 \mathrm{e}-\mathrm{h}$ & - \\
\hline & I & 0.05 ef & 56.9 & $0.29 \mathrm{f}-\mathrm{i}$ & 4.7 & $0.06 \mathrm{~d}-\mathrm{f}$ & 116.4 & $0.30 \mathrm{~h}$ & -2.0 \\
\hline & $\mathrm{BF}$ & $0.04 \mathrm{f}$ & 15.0 & $0.30 \mathrm{e}-\mathrm{h}$ & 6.5 & $0.07 \mathrm{de}$ & 185.0 & $0.29 \mathrm{f}-\mathrm{h}$ & -1.3 \\
\hline & $\mathrm{CF}$ & 0.05 ef & 52.1 & $0.29 \mathrm{~g}-\mathrm{i}$ & 3.2 & $0.06 \mathrm{~d}-\mathrm{f}$ & 151.6 & $0.30 \mathrm{f}-\mathrm{h}$ & -0.7 \\
\hline & $1 / 2 \mathrm{CF}$ & 0.04 ef & 31.7 & $0.28 \mathrm{hi}$ & 2.1 & 0.04 ef & 62.2 & $0.30 \mathrm{~d}-\mathrm{h}$ & 0 \\
\hline & $\mathrm{I}+\mathrm{CF}$ & $0.06 \mathrm{~d}-\mathrm{f}$ & 78.1 & $0.29 \mathrm{~g}-\mathrm{i}$ & 4.0 & $0.05 \mathrm{~d}-\mathrm{f}$ & 106.7 & $0.31 \mathrm{a}-\mathrm{e}$ & 5.1 \\
\hline & $\mathrm{I}+1 / 2 \mathrm{CF}$ & $0.05 \mathrm{ef}$ & 42.8 & $0.30 \mathrm{c}-\mathrm{h}$ & 7.2 & $0.05 \mathrm{ef}$ & 85.8 & $0.31 \mathrm{a}-\mathrm{f}$ & 3.4 \\
\hline
\end{tabular}

Values with the same letter(s) are not significantly different from each other according to the LSD test $(P>0.05)$

$I$ inoculation of seed using beneficial bacterial consortium. Pots were also inoculated by bacterial suspension every 3 weeks; $B F$ seed treatment with commercial bio-fertilizer. Pots were also treated every 3 weeks, simultaneously to the PGPB treatment; $C F$ adding full dose of recommended chemical fertilizers to the soil; $1 / 2 C F$ half-dose of recommended chemical fertilizers; $C o$ control treatment (no chemical and microbiological fertilizer)

the unfertilized plants under non-stress conditions. Accordingly, the higher rate of stomatal conductance was observed in $\mathrm{I}+\mathrm{CF}$, which was significantly greater than control, $\mathrm{BF}$ and $1 / 2 \mathrm{CF}$, but was not statistically superior to the $\mathrm{CF}$, $\mathrm{I}$ and $\mathrm{I}+1 / 2 \mathrm{CF}$. This parameter varied from 0.033 (Co at the severe drought) and 0.025 (Co at the severe salinity) to $0.168 \mathrm{mmol} \mathrm{m}^{-2} \mathrm{~s}^{-1}$ (CF in unstressed plants) (Table 2). However, the same results were recorded at the mild and severe levels of drought, but more interesting results were obtained from salinity stress. In this respect, only the plants treated with chemical fertilizer ( $\mathrm{CF}$ and $1 / 2 \mathrm{CF}$ ) had higher rate of stomatal conductance in comparison with unfertilized plants at the mild level of salinity, while this rate was non-significantly decreased by other fertilizer treatments (Table 2).

All fertilization treatments significantly improved the grain yield in comparison with unfertilized treatment in both unstressed and stressed plants. Under non-stress, grain yield reached the maximum value, 1.15 gr per plant, in $\mathrm{I}+\mathrm{CF}$ treatment $(\sim 121,53,13$ and $9 \%$ higher than the unfertilized treatment, and I, CF and $\mathrm{I}+1 / 2 \mathrm{CF}$ treated plants, respectively). Similar results were observed in the mild drought and in both mild and severe salinity, while the maximum grain yield under the severe drought obtained by I and $\mathrm{I}+1 / 2 \mathrm{CF}$ treatments, equal to 0.46 and 0.44 gr per plant, respectively. Moreover, the effect of PGPB inoculation (I) on grain yield was lower (-13\%) than CF in the mild salinity, while its effect was higher $(+3 \%)$ in the severe salinity level (Table 3). Similarly, in both mild and severe drought, the heights of inoculated plants were 60 and $59 \mathrm{~cm}$, which was 2 and $13 \%$ higher than the $\mathrm{I}+\mathrm{CF}$ treatment, respectively. Conversely, the tallest plants were found in $\mathrm{I}+\mathrm{CF}$ treatment under the mild and severe salinity, which were 3 and $6 \%$ taller than I treatment, respectively (Table 3). 
Table 3 Durum wheat grain yield and plant height as affected by fertilization and stress treatments, as well as their increment rates in comparison to the unfertilized treatment in each stress level

\begin{tabular}{|c|c|c|c|c|c|c|c|c|c|}
\hline \multirow[t]{3}{*}{ Stress } & \multirow[t]{3}{*}{ Fertilizer } & \multicolumn{4}{|l|}{ Drought } & \multicolumn{4}{|l|}{ Salinity } \\
\hline & & Grain yield & Increment rate & Plant height & Increment rate & Grain yield & Increment rate & Plant height & Increment rate \\
\hline & & $\mathrm{g} /$ plant & $\%$ & $\mathrm{~cm}$ & $\%$ & $\mathrm{~g} / \mathrm{plant}$ & $\%$ & $\mathrm{~cm}$ & $\%$ \\
\hline \multirow[t]{7}{*}{ Control } & Co & $0.52 \mathrm{gh}$ & - & $61.00 \mathrm{~cd}$ & - & $0.52 \mathrm{ij}$ & - & $61.00 \mathrm{fg}$ & - \\
\hline & I & $0.75 \mathrm{~cd}$ & 45.0 & $71.00 \mathrm{a}$ & 16.4 & $0.75 \mathrm{de}$ & 45.0 & $71.00 \mathrm{a}$ & 16.4 \\
\hline & $\mathrm{BF}$ & $0.64 \mathrm{e}$ & 23.3 & $67.67 \mathrm{ab}$ & 10.9 & $0.64 \mathrm{f}-\mathrm{h}$ & 23.3 & $67.67--\mathrm{c}$ & 10.9 \\
\hline & $\mathrm{CF}$ & $1.03 \mathrm{~b}$ & 98.3 & $68.33 \mathrm{ab}$ & 12.0 & $1.03 \mathrm{~b}$ & 98.3 & $68.33 \mathrm{a}-\mathrm{c}$ & 12.0 \\
\hline & $1 / 2 \mathrm{CF}$ & $0.60 \mathrm{ef}$ & 16.2 & $64.00 \mathrm{bc}$ & 4.9 & $0.60 \mathrm{~g}-\mathrm{i}$ & 16.2 & $64.00 \mathrm{c}-\mathrm{f}$ & 4.9 \\
\hline & $\mathrm{I}+\mathrm{CF}$ & $1.15 \mathrm{a}$ & 121.1 & $68.33 \mathrm{ab}$ & 12.0 & $1.15 \mathrm{a}$ & 121.1 & $68.33 \mathrm{a}-\mathrm{c}$ & 12.0 \\
\hline & $\mathrm{I}+1 / 2 \mathrm{CF}$ & $1.05 \mathrm{~b}$ & 102.1 & $69.33 \mathrm{ab}$ & 13.7 & $1.05 \mathrm{ab}$ & 102.1 & $69.33 \mathrm{a}$ & 13.7 \\
\hline \multirow[t]{7}{*}{ Mild stress } & $\mathrm{Co}$ & $0.35 \mathrm{~lm}$ & - & $55.33 \mathrm{~d}-\mathrm{g}$ & - & $0.36 \mathrm{k}$ & - & $61.00 \mathrm{fg}$ & - \\
\hline & I & $0.54 \mathrm{fg}$ & 55.1 & $60.00 \mathrm{c}-\mathrm{e}$ & 8.4 & $0.76 \mathrm{c}-\mathrm{e}$ & 111.9 & $67.33 \mathrm{a}-\mathrm{d}$ & 8.6 \\
\hline & $\mathrm{BF}$ & $0.47 \mathrm{~g}-\mathrm{i}$ & 35.1 & $57.33 \mathrm{~d}-\mathrm{f}$ & 3.6 & $0.62 \mathrm{~g}-\mathrm{i}$ & 71.9 & $63.00 \mathrm{~d}-\mathrm{g}$ & 1.6 \\
\hline & $\mathrm{CF}$ & $0.76 \mathrm{~cd}$ & 116.6 & $57.67 \mathrm{c}-\mathrm{f}$ & 4.2 & $0.86 \mathrm{c}$ & 137.8 & $67.00 \mathrm{a}-\mathrm{e}$ & 8.1 \\
\hline & $1 / 2 \mathrm{CF}$ & $0.40 \mathrm{i}-1$ & 14.6 & $55.33 \mathrm{~d}-\mathrm{g}$ & 0.0 & $0.63 \mathrm{gh}$ & 74.2 & $66.67 \mathrm{a}-\mathrm{e}$ & 7.5 \\
\hline & $\mathrm{I}+\mathrm{CF}$ & $0.83 \mathrm{c}$ & 135.7 & $59.00 \mathrm{c}-\mathrm{e}$ & 6.3 & $0.86 \mathrm{c}$ & 138.7 & $69.33 \mathrm{a}$ & 11.8 \\
\hline & $\mathrm{I}+1 / 2 \mathrm{CF}$ & $0.72 \mathrm{~d}$ & 104.8 & $57.67 \mathrm{c}-\mathrm{f}$ & 4.2 & 0.73 ef & 103.6 & $62.67 \mathrm{e}-\mathrm{g}$ & 1.1 \\
\hline \multirow[t]{7}{*}{ Severe stress } & Co & $0.26 \mathrm{n}$ & - & $46.33 \mathrm{~h}$ & - & $0.35 \mathrm{k}$ & - & $51.67 \mathrm{i}$ & - \\
\hline & I & $0.46 \mathrm{~h}-\mathrm{j}$ & 78.1 & $59.00 \mathrm{c}-\mathrm{e}$ & 27.3 & $0.61 \mathrm{~g}-\mathrm{i}$ & 73.1 & $64.67 \mathrm{~b}-\mathrm{f}$ & 25.2 \\
\hline & $\mathrm{BF}$ & $0.29 \mathrm{mn}$ & 11.2 & $50.00 \mathrm{gh}$ & 7.9 & $0.54 \mathrm{~h}-\mathrm{j}$ & 55.4 & $58.67 \mathrm{gh}$ & 13.5 \\
\hline & $\mathrm{CF}$ & $0.40 \mathrm{j}-\mathrm{k}$ & 51.9 & $54.00 \mathrm{e}-\mathrm{g}$ & 16.5 & $0.59 \mathrm{~g}-\mathrm{i}$ & 69.7 & $59.33 \mathrm{gh}$ & 14.8 \\
\hline & $1 / 2 \mathrm{CF}$ & $0.29 \mathrm{mn}$ & 11.2 & $54.00 \mathrm{e}-\mathrm{g}$ & 16.5 & $0.49 \mathrm{j}$ & 38.6 & $55.33 \mathrm{hi}$ & 7.1 \\
\hline & $\mathrm{I}+\mathrm{CF}$ & $0.38 \mathrm{kl}$ & 47.3 & $52.00 \mathrm{f}-\mathrm{h}$ & 12.2 & $0.69 \mathrm{e}-\mathrm{g}$ & 96.0 & $68.67 \mathrm{ab}$ & 32.9 \\
\hline & $\mathrm{I}+1 / 2 \mathrm{CF}$ & $0.44 \mathrm{i}-\mathrm{k}$ & 67.3 & $55.33 \mathrm{~d}-\mathrm{g}$ & 19.4 & $0.55 \mathrm{~h}-\mathrm{j}$ & 56.9 & $59.33 \mathrm{gh}$ & 14.8 \\
\hline
\end{tabular}

Values with the same letter(s) are not significantly different from each other according to the LSD test $(P>0.05)$

$I$ inoculation of seed using beneficial bacterial consortium. Pots were also inoculated by bacterial suspension every 3 weeks; $B F$ seed treatment with commercial bio-fertilizer. Pots were also treated every 3 weeks, simultaneously to the PGPB treatment; $C F$ adding full dose of recommended chemical fertilizers to the soil; $1 / 2 C F$ half-dose of recommended chemical fertilizers; $C o$ control treatment (no chemical and microbiological fertilizer)

Following the regression of the linear model, the relationships between the grain yield and photosynthesis capacity significantly fitted under drought $\left(R^{2}=0.70\right.$; $P<0.01)$ and salinity $\left(R^{2}=0.39 ; P<0.05\right)$ conditions (Fig. 3). The multiple linear regression (backward elimination method) was used to explain which of the main photosynthetic variables could be more useful to estimate the photosynthetic capacity of plants under fertilization treatments and stress conditions. The results indicated a quite different response of leaves to the drought and salinity stress. Accordingly, transpiration rate, $\mathrm{Y}(\mathrm{NPQ}), \mathrm{Y}(\mathrm{NO})$ and $\mathrm{Y}(\mathrm{II})$ were identified as the independent variables which had the most impact on photosynthetic capacity (dependent variable) in the drought-stress condition $\left(R^{2}=0.96\right)$. On the other hand, stomatal conductance seems to be more useful to predict the photosynthetic capacity under salinity stress $\left(R^{2}=0.88\right)$. The rankings of the parameters were stomatal conductance $>\mathrm{Y}(\mathrm{NPQ})>\mathrm{Y}(\mathrm{NO})>\mathrm{Chl}$

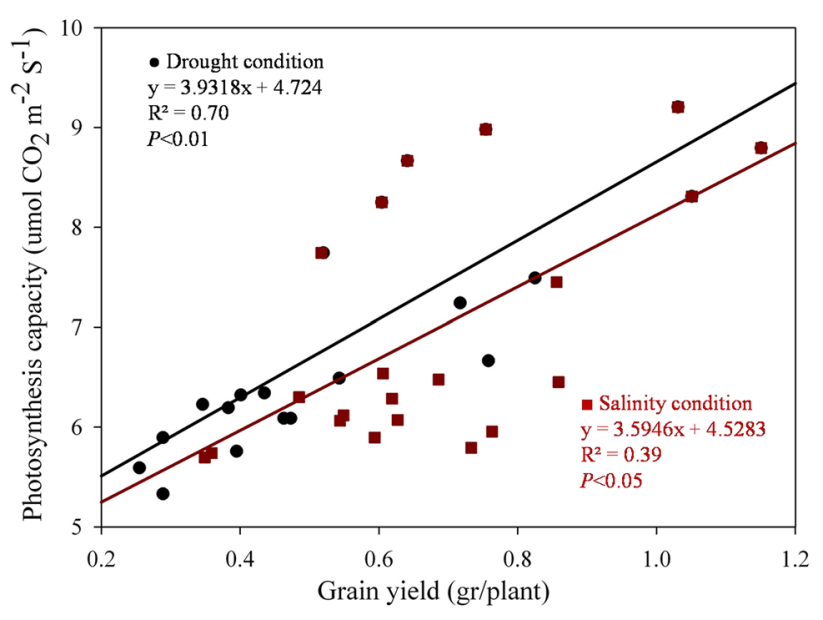

Fig. 3 The relationship between grain yield and photosynthesis capacity as affected by fertilization and stress treatments 
Table 4 Multiple linear regressions (backward method) among photosynthetic capacity (dependent variable) and 7 photosynthetic variables (independent variables) influenced by fertilization management under stress conditions $(N=21)$

\begin{tabular}{|c|c|c|c|c|c|c|}
\hline \multirow[t]{2}{*}{ Model } & \multicolumn{3}{|l|}{ Drought stress } & \multicolumn{3}{|l|}{ Salinity stress } \\
\hline & Independent variables & $\begin{array}{l}\text { Standardized coef- } \\
\text { ficients (Beta) }\end{array}$ & Significance level & Independent variables & \multirow[t]{2}{*}{$\begin{array}{l}\text { Standardized coef- } \\
\text { ficients (Beta) }\end{array}$} & Significance level \\
\hline \multirow[t]{8}{*}{1} & \multicolumn{2}{|l|}{ (Constant) } & 0.149 & (Constant) & & 0.811 \\
\hline & Stomatal conductance & 0.242 & 0.273 & Stomatal conductance & 0.649 & 0.118 \\
\hline & Transpiration capacity & 0.770 & 0.010 & Transpiration capacity & 0.143 & 0.754 \\
\hline & Chl concentration & -0.101 & 0.281 & Chl concentration & -0.096 & 0.508 \\
\hline & $\mathrm{Y}(\mathrm{NPQ})$ & 3.037 & 0.142 & $\mathrm{Y}(\mathrm{NPQ})$ & -0.166 & 0.766 \\
\hline & $\mathrm{Y}(\mathrm{NO})$ & 2.916 & 0.142 & $\mathrm{Y}(\mathrm{NO})$ & -0.178 & 0.756 \\
\hline & $\mathrm{Y}(\mathrm{II})$ & 7.351 & 0.123 & $\mathrm{Y}(\mathrm{II})$ & 0.526 & 0.903 \\
\hline & ETR & -1.838 & 0.503 & ETR & -0.563 & 0.900 \\
\hline 2 & (Constant) & & 0.144 & (Constant) & & 0.815 \\
\hline & Stomatal conductance & 0.305 & 0.127 & Stomatal conductance & 0.641 & 0.104 \\
\hline & Transpiration capacity & 0.720 & 0.010 & Transpiration capacity & 0.160 & 0.703 \\
\hline & Chl concentration & -0.115 & 0.206 & Chl concentration & -0.090 & 0.495 \\
\hline & $\mathrm{Y}(\mathrm{NPQ})$ & 2.997 & 0.138 & $\mathrm{Y}(\mathrm{NPQ})$ & -0.153 & 0.771 \\
\hline & $\mathrm{Y}(\mathrm{NO})$ & 2.908 & 0.134 & $\mathrm{Y}(\mathrm{NO})$ & -0.166 & 0.760 \\
\hline & $\mathrm{Y}(\mathrm{II})$ & 5.741 & 0.135 & ETR & -0.028 & 0.975 \\
\hline 3 & (Constant) & & 0.057 & (Constant) & & 0.017 \\
\hline & Stomatal conductance & 0.185 & 0.290 & Stomatal conductance & 0.643 & 0.090 \\
\hline & Transpiration capacity & 0.793 & 0.005 & Transpiration Capacity & 0.59 & 0.694 \\
\hline & $\mathrm{Y}(\mathrm{NPQ})$ & 3.858 & 0.053 & Chl concentration & -0.089 & 0.449 \\
\hline & $\mathrm{Y}(\mathrm{NO})$ & 3.720 & 0.052 & $\mathrm{Y}(\mathrm{NPQ})$ & -0.138 & 0.242 \\
\hline & $\mathrm{Y}(\mathrm{II})$ & 6.955 & 0.055 & $\mathrm{Y}(\mathrm{NO})$ & -0.150 & 0.320 \\
\hline 4 & (Constant) & & 0.048 & (Constant) & & 0.003 \\
\hline & Transpiration capacity & 0.995 & 0.000 & Stomatal conductance & 0.774 & 0.000 \\
\hline & $\mathrm{Y}(\mathrm{NPQ})$ & 4.044 & 0.043 & Chl concentration & -0.095 & 0.399 \\
\hline & $\mathrm{Y}(\mathrm{NO})$ & 3.879 & 0.044 & $\mathrm{Y}(\mathrm{NPQ})$ & -0.156 & 0.145 \\
\hline & $\mathrm{Y}(\mathrm{II})$ & 7.243 & 0.047 & $\mathrm{Y}(\mathrm{NO})$ & -0.172 & 0.212 \\
\hline 5 & - & - & - & (Constant) & & 0.002 \\
\hline & - & - & - & Stomatal conductance & 0.736 & 0.000 \\
\hline & - & - & - & $\mathrm{Y}(\mathrm{NPQ})$ & -0.125 & 0.204 \\
\hline & - & - & - & $\mathrm{Y}(\mathrm{NO})$ & -0.160 & 0.236 \\
\hline 6 & - & - & - & (Constant) & & 0.001 \\
\hline & - & - & - & Stomatal conductance & 0.848 & 0.000 \\
\hline & - & - & - & $\mathrm{Y}(\mathrm{NPQ})$ & -0.157 & 0.105 \\
\hline 7 & - & - & - & (Constant) & & 0.000 \\
\hline & - & - & - & Stomatal conductance & 0.942 & 0.000 \\
\hline Model & mary & & & & & \\
\hline Model & & ted $R$ square & Std. error of & stimate & ted $R$ square & $\begin{array}{l}\text { Std. error of } \\
\text { the estimate }\end{array}$ \\
\hline 1 & & & 0.257 & & & 0.443 \\
\hline 2 & & & 0.247 & & & 0.427 \\
\hline 3 & & & 0.254 & & & 0.412 \\
\hline 4 & & & 0.255 & & & 0.401 \\
\hline 5 & - & & - & & & 0.398 \\
\hline 6 & - & & - & & & 0.404 \\
\hline 7 & - & & - & & & 0.424 \\
\hline
\end{tabular}

Constant $y$-intercept, the value at which the regression line crosses the $y$-axis; $Y(I I)$ effective quantum efficiency of PSII; $Y(N P Q)$ quantum yield of light-induced non-photochemical quenching; $Y(N O)$ quantum yield of non-regulated energy dissipation; ETR photosynthetic electron transport rate 
concentration $>$ transpiration capacity $>$ ETR $>$ Y(II) (Table 4).

\section{Discussion}

The present research aimed to test four beneficial bacterial strains belonging to Acinetobacter and Comamonas genera, as bio-inoculant (applied alone or combined with the recommended dose or half-dose of the chemical fertilizers), as well as a commercial bio-fertilizer, on leaf photosynthetic capacity of durum wheat, in non-stress and stress (mild and severe saline and drought) conditions. Our PGPB strains had enormous ability to transform the insoluble phosphate, potassium and zinc in the soil into soluble forms, to produce indole acetic acid (IAA), as well as to fix $\mathrm{N}_{2}$ gas (Yaghoubi Khanghahi et al. 2020). It has already been reported that the nutrients supplied by fertilizers play a crucial role in the photosynthetic machinery structures, containing various mechanisms, such as gas exchange systems, yield of PSII photochemistry and electron transport chain, as well as biosynthesis of chlorophyll (Yong et al. 2010; Acosta-Motos et al. 2017). In accordance with our results, there are many studies that reported the increment of grain yield and plant height in response to PGPB inoculation (Meena et al. 2017; Yaghoubi Khanghahi et al. 2018c).

Plants treated with combined treatments of PGPB inoculants and chemicals $(\mathrm{I}+1 / 2 \mathrm{CF}$ and $\mathrm{I}+\mathrm{CF}$ ) had significantly higher Chl $a$ content and chlorophyll concentration than untreated control plants in both stress and non-stress conditions. Actually, the increment of leaf chlorophyll concentration, as the light-harvesting antenna associated with PSI and PSII reaction center in the thylakoid membrane, can protect the photosynthetic machinery upon subsequent application of PGPB inoculation, likely owing to enhanced production of IAA (Kanagendran et al. 2019), 1-aminocyclopropane-1-carboxylate (ACC) deaminase activity (Kumar et al. 2019) and bio-availability of soil nutrients (Yaghoubi Khanghahi et al. 2018b; Hagaggi and Mohamed 2020). A significant relationship between plant photosynthetic pigments and leaf nutrient concentration, such as N, P and K, has been widely found in crops (Liu et al. 2019; Yaghoubi Khanghahi et al. 2019a).

Similar to our findings, Shah et al. (2017) reported the decrease in Chl $a$ content and SPAD values in wheat leaves under stress. Also, the increment of $8-12 \%$ in Chl content and SPAD value was found by inoculations of $\mathrm{P}$ and $\mathrm{K}$ solubilizing bacteria as compared to non-inoculated seedlings (Bakhshandeh et al. 2015, 2018). On the other hand, $\mathrm{Chl} b$ and carotenoids increased in our research, especially in PGPB-inoculated plants, under mild stress levels. This may be due to the different response of pigments under environmental stress (Bahari et al. 2013; Sayyad-Amin et al. 2016). In fact, carotenoids, composed of carotenes and xanthophylls, have the fundamental role in harvesting light energy for photosynthesis, dissipating of excess light energy and providing protection to reaction centers under stress (Acosta-Motos et al. 2017). Moreover, the increase in $\mathrm{Chl} b$ could be most probably due to an increase in the amount of the major antenna complex of PSII where Chl $b$ is bound (Yaghoubi Khanghahi et al. 2019a).

$F_{\mathrm{v}} / F_{\mathrm{m}}$ ratio in the present research was observed from 0.777 to 0.799 . This parameter, expressing the maximum efficiency of PSII photochemistry in dark-adapted leaves, has been usually reported between 0.79 and 0.85 in unstressed plants (Chojak-Kozniewska et al. 2018; Malinská et al. 2020). Nevertheless, it is proved that $F_{\mathrm{v}} / F_{\mathrm{m}}$ ratio is less sensitive and responsive to the stresses in comparison with the effective quantum yield of PSII (Y(II)) (Malinská et al. 2020), especially to the mild stress conditions (Salvatori et al. 2017). In fact, the ChlF originates from de-excitation of the first excited singlet-state of Chla molecules (Roháček 2002) and has a significant correlation with Chl content (Yaghoubi Khanghahi et al. 2019a). Therefore, this can explain why the main ChlF parameters, such as Y(II), ETR, $\mathrm{Y}(\mathrm{NPQ})$ and $\mathrm{Y}(\mathrm{NO})$, were most affected by the same treatments which had the greatest effect on Chl content (PGPB inoculation, especially in combination with the half-dose of $\mathrm{CF}$ ) under both non-stress and stress conditions.

It has also been reported that stress can result in decreasing in ETR and Y(II) in the photochemical quenching process, while increasing in qN, NPQ, and $\mathrm{Y}(\mathrm{NPQ})$ as nonphotochemical quenching mechanisms (Acosta-Motos et al. 2015; Ikbal et al. 2014). When the absorbed light energy by the photosystem in the stressed plants is over the photosynthesis capacity, NPQ, as an energy-dissipative mechanism in PSII, significantly increases (Jia et al. 2008). Other mechanisms are Y(NPQ) and Y(NO), which are defined as the yield for dispersion by down regulatory processes and the other non-photochemical energy losses, respectively (Kramer et al. 2004). In the current research, due to the greater photochemical efficiency of the PSII (Y(II)) in the fertilized-treated plants, the increment in NPQ, Y(NPQ), and $\mathrm{Y}(\mathrm{NO})$ rates were lower than those in control plants. However, NPQ and Y(NPQ) at the severe level of drought and $\mathrm{Y}(\mathrm{NO})$ at the mild and severe levels of salinity were not significantly influenced by fertilization treatments. This may be evidence of different mechanisms of plants to tolerate stressful situations. Similarly, Shu et al. (2013) stated that the stress intensity and its duration affect how the photochemical and non-photochemical quenching parameters in plants change. Also, in all drought levels, the maximum Y(II) was detected in plants under half-dose of CF combined with the PGPB inoculations. Similar results were observed for photosynthesis capacity, stomatal conductance and transpiration 
rate, as the bacterial inoculation treatment improved these parameters, especially at half-dose of $\mathrm{CF}$, as compared to the full dose of CF. The main explanation of these findings may be related to the accumulation of salts in the soil due to large amounts of chemical fertilizers application (Evangelou 1983). In our case, this problem was associated with drought stress and affected photosynthesis traits, particularly at the severe level of drought. These findings are consistent with Zulkarami et al. (2012), who reported that the accumulation of salts in the soil during plant growth due to the higher electrical conductivity levels of chemical fertilizers also affected the effectiveness of bio-inoculants.

Since it has already proved that ETR was slightly decreased in stress-tolerant plants (Acosta-Motos et al. 2017) and there is also a high correlation between ETR and $\mathrm{CO}_{2}$ assimilation rate in plants (Maxwell and Johnson 2000), it seems that our bio-inoculants treatments are able to alleviate the negative effects of stresses, in particular the salinity, as compared to the unfertilized treatment. Similarly, Li et al. (2013) and Yaghoubi Khanghahi et al. (2019a) reported the positive impacts of soil beneficial microorganisms on mitigation of the inhibition of the PSII reaction center, increasing the ETR and consequently improving the photochemical process and light transformation.

Decreases in stomatal conductance, as an indicator of tolerance to stress, have been reported in several previous studies under stress conditions (Gómez-Bellot et al. 2013; Acosta-Motos et al. 2017). Regression analysis indicated that stomatal conductance had lower relation to ETR and $\mathrm{Y}(\mathrm{II})$ in the saline stress condition and seems to be more independent from stomatal conductance on that condition as compared to the drought. Since ETR and Y(II) under drought were lower than those in saline stress (as shown in figure S1), it can be supposed that the photo-inhibition was exacerbated under drought due to the excitation of excess energy dissipation (Wang et al. 2016). It can be concluded that the durum wheat fertilized-plants under saline stress had more ability to keep photosynthesis instead of alternative electron consuming processes, such as photorespiration and Mehler reactions (Flexas and Medrano 2002; Yaghoubi Khanghahi et al. 2019a), due to a greater potential to maintain their ETR capability and Y(II) efficiency under lower stomatal conductance values. On the other hand, linear models related to grain yield and photosynthesis capacity showed the lower relationship under salinity $\left(R^{2}=0.39 ; P<0.05\right)$ than that in drought $\left(R^{2}=0.70 ; P<0.01\right)$, however, both relations were statistically significant. This is a sign of the interactions of photosynthetic sink-source balance in crops under different conditions limiting growth, which showed that the photosynthesis capacity may make a contribution in growing plant organs and stem elongation rather than sink organs (grain) under salinity, as compared to the drought.
Given the results of the current research, at the mild salinity level, stomatal conductance in plants under PGPB inoculation and commercial bio-fertilizer treatments was lower than that in the unfertilized plants, while this parameter nonsignificantly increased by chemical fertilizer treatments at the same salinity level (mild). Moreover, almost the same trend was observed for Chl $a$, Chl concentration, $F_{\mathrm{v}} / F_{\mathrm{m}}$, ETR, Y(II), transpiration capacity and photosynthesis rate, which were lower in mild salinity stress than the severe salinity and non-stress levels. It seems that mild salinity $(75 \mathrm{mM} \mathrm{NaCl})$ did not induce the PGPB-plant interactions to activate some specific salt tolerance mechanisms, as they were probably active in severe salinity. However the grain yield in inoculated plants by I treatment, as well as the plant height in all fertilization treatments, did not change significantly under mild salinity in comparison to the unstressed plants, while the grain yield in $\mathrm{CF}$ treatments $(\mathrm{CF}, \mathrm{I}+1 / 2 \mathrm{CF}$ and $\mathrm{I}+\mathrm{CF})$ decreased under mild salinity. This could be interpreted by the capability of our PGPB, especially Comamonas testosteroni (a $\mathrm{N}_{2}$ fixing bacterium), which showed the higher growth under salt stress ( $1 \% \mathrm{NaCl}$ concentration) in vitro condition (Yaghoubi Khanghahi et al. 2020), as compared to the common PGPB. Probably, this is the reason why the amount of these parameters in severe salinity was higher than those in severe drought, when PGPB inoculation was applied. It has already proved that PGPB can help the crop plants to cope with the salinity by the accumulation of osmoprotectants and phytohormones signaling (Vandana et al. 2020), the improvement of ion homeostasis and transport (Ilangumaran and Smith 2017), the expression of the specific genes (Nautiyal et al. 2013) and by affecting the carbohydrate metabolism and transport, as the main key source-sink relationship, which can result in enhanced photosynthesis capacity (Vandana et al. 2020).

Plants regulate the transpiration process by controlling the stomata on the leaf surface, which play a crucial role in maintaining water balance in the leaves under stress. Therefore, the lower stomatal conductance in unfertilized treatment under stress resulted in a lower transpiration rate. Rising temperature in the plant canopy can occur under stress, especially in severe drought, due to the transpiration via the cuticle, which can lead to stomatal closure and a higher respiration rate in plant tissues (Acosta-Motos et al. 2017). This condition can result in lower photosynthetic capacity under stress, particularly in unfertilized treatment. Nevertheless, the decline in stomatal conductance and transpiration rate is one of the causes of the photosynthetic capacity reduction, because this parameter can be also dropped owing to other non-stomatal limitations, such as the disturbance of the photosynthetic electron chain and/or the inhibition of the Calvin Cycle enzymes (Chaves et al. 2009; Acosta-Motos et al. 2017). This could be the main explanation why there was a difference between drought and salinity in terms of 
prediction of the photosynthesis capacity, as analyzed by multiple linear regressions. Accordingly, stomatal conductance was identified as the main parameter affecting photosynthesis capacity in salt-treated plants. Therefore, in our research, restriction of photosynthetic capacity in the salinity was closely associated with stomatal rather than non-stomatal factors. In contrast, transpiration rate, $\mathrm{Y}(\mathrm{NPQ}), \mathrm{Y}(\mathrm{NO})$ and Y(II) were the most important variables affecting photosynthetic capacity in drought-treated plants. Although it has been reported that the early plants' responses to drought and salinity are very similar (Navarro et al. 2008), our results indicated different responses to the long-term stress, especially by the application of PGPB inoculation combined with the $\mathrm{CF}$.

In the light of the results, the consortium of our native PGPB strains, notably in combination with half-dose of chemicals, can be utilized not only for upgrading the PSII photochemical system in non-stress condition, but also for maintaining the function of photosynthetic system under drought and salinity, and consequently contributing to enhanced grain yield. In fact, bacterial inoculation was able to compete with half and full doses of CF. As already reported, the application of PGPB inoculation can reduce the consumption of chemicals (Yaghoubi Khanghahi et al. 2018c) and augment their efficiency (Yaghoubi Khanghahi et al. 2019b; Bakhshandeh et al. 2020) to achieve sustainable crops' productivity (Meena et al. 2017). Furthermore, the combination of efficient PGPB can induce systemic tolerance against drought and salinity via several direct and indirect mechanisms (Vandana et al. 2020).

\section{Conclusion}

Our results showed that the utilization of beneficial bacterial inoculants, as a bacterial consortium, can improve some photosynthetic parameters when compared to traditional fertilization plans, posing a valid alternative for a sustainable agriculture. More relevantly, the PGPB inoculation markedly improved some biochemical and functional traits in photosystem II, such as the effective quantum yield of PSII (Y(II)), the electron transport rate of PSII (ETR), the photosynthesis capacity, the stomatal conductance and the transpiration rate in unstressed plants, and prevented drastic changes in the mentioned traits under drought and salinity conditions. We also found a better performance of the PGPB inoculation in combination with half-dose of the recommended chemical fertilizers. Therefore, PGPB inoculants can help to minimize the use of chemical fertilizers by maintaining the photosynthesis efficiency of durum wheat leaves, particularly under stress conditions.
Author contribution statement MYK: experimental procedures, data acquisition and elaboration, draft preparation. BL: experimental set up supervision, experimental procedures. CC: supervision, manuscript preparation, corresponding author.

Supplementary Information The online version contains supplementary material available at https://doi.org/10.1007/s11738-021-03289-z.

Acknowledgements The authors would like to thank Professor Francesco Faretra from the Department of Soil, Plant and Food Sciences, and Professor Pietro Santamaria from the Department of Soil, Plant and Food Sciences and Department of Agricultural and Environmental Science, University of Bari Aldo Moro for providing the use of the greenhouse and of some facilities, respectively. The authors also thank Professor Angelo Signore and Miguel Robalo for their technical assistance.

Funding Open access funding provided by Università degli Studi di Bari Aldo Moro within the CRUI-CARE Agreement.

\section{Declarations}

Conflict of interest No conflict of interest declared.

Open Access This article is licensed under a Creative Commons Attribution 4.0 International License, which permits use, sharing, adaptation, distribution and reproduction in any medium or format, as long as you give appropriate credit to the original author(s) and the source, provide a link to the Creative Commons licence, and indicate if changes were made. The images or other third party material in this article are included in the article's Creative Commons licence, unless indicated otherwise in a credit line to the material. If material is not included in the article's Creative Commons licence and your intended use is not permitted by statutory regulation or exceeds the permitted use, you will need to obtain permission directly from the copyright holder. To view a copy of this licence, visit http://creativecommons.org/licenses/by/4.0/.

\section{References}

Acosta-Motos JR, Díaz-Vivancos P, Álvarez S, Fernández-García N, Sánchez-Blanco MJ, Hernández JA (2015) NaCl-induced physiological and biochemical adaptative mechanism in the ornamental Myrtus cummunis L. plants. J Plant Physiol 183:41-51

Acosta-Motos JR, Ortuño MF, Bernal-Vicente A, Diaz-Vivancos P, Sanchez-Blanco MJ, Hernandez JA (2017) Plant responses to salt stress: adaptive mechanisms. Agronomy 7:18

Bahari A, Pirdashti H, Yaghoubi M (2013) The effects of amino acid fertilizers spraying on photosynthetic pigments and antioxidant enzymes of wheat (Triticum aestivum L.) under salinity stress. Int J Agron Plant Prod 4(4):787-793

Bakhshandeh E, Rahimian H, Pirdashti H, Nematzadeh GA (2015) Evaluation of phosphate-solubilizing bacteria on the growth and grain yield of rice (Oryza sativa L.) cropped in northern Iran. J Appl Microbiol 119:1371-1382

Bakhshandeh E, Pirdashti H, Gilani Z (2018) Application of mathematical models to describe rice growth and nutrients uptake in the presence of plant growth promoting microorganisms. Appl Soil Ecol 124:171-184 
Bakhshandeh E, Pirdashti H, Shahsavarpour Lendeh Kh, Gilani Z, Yaghoubi Khanghahi M, Crecchio C (2020) Effects of plant growth promoting microorganisms inoculums on mineral nutrition, growth and productivity of rice (Oryza sativa L.). J Plant Nutr. https://doi.org/10.1080/01904167.2020.1739297

Balasubramanian V, Buresh RJ, Bell M (2015) International Rice Research Institute. http://www.knowledgebank.irri.org.

Bilger W, Björkman O (1990) Role of the xanthophyll cycle in photoprotection elucidated by measurements of light-induced absorbance changes, fluorescence and photosynthesis in leaves of Hedera canariensis. Photosynth Res 25:173-185

Chairi F, Sanchez-Bragado R, Serret MD, Aparicio N, Nieto-Taladriz MT, Araus JL (2019) Agronomic and physiological traits related to the genetic advance of semi-dwarf durum wheat: the case of Spain. Plant Sci 295:110210

Chatterjee P, Samaddar S, Niinemets Ü, Sa TM (2018) Brevibacterium linens RS16 confers salt tolerance to Oryza sativa genotypes by regulating antioxidant defence and $\mathrm{H}+$ ATPase activity. Microbiol Res 215:89-101

Chaves MM, Flexas J, Pinheiro C (2009) Photosynthesis under drought and salt stress: regulation mechanisms from whole plant to cell. Ann Bot 103:551-560

Chojak-Kozniewska J, Kuznika E, Linkiewicz A, Sowa S (2018) Primary carbon metabolism-related changes in cucumber exposed to single and sequential treatments with salt stress and bacterial infection. Plant Physiol Biochem 123:160-169

Duncan EG, O’Sullivan CA, Roper MM, Biggs JS, Peoples MB (2018) Influence of co-application of nitrogen with phosphorus, potassium and sulphur on the apparent efficiency of nitrogen fertiliser use, grain yield and protein content of wheat: review. Field Crop Res 226:56-65

Evangelou VP (1983) Effect of fertilizer salts on crop production. Soil Sci News Views. 164. https://uknowledge.uky.edu/pss_views/164

Flexas J, Medrano H (2002) Drought-inhibition of photosynthesis in C3 plants: stomatal and non-stomatal limitations revisited. Ann Bot 89:183-189

Genty B, Briantais JM, Baker NR (1989) The relationship between the quantum yield of photosynthetic electron transport and quenching of ChlF. Biochim Biophys Acta 99:87-92

Gómez-Bellot MJ, Álvarez S, Castillo M, Bañón S, Ortuño MF, Sánchez-Blanco MJ (2013) Water relations, nutrient content and developmental responses of Euonymus plants irrigated with water of different degrees of salinity and quality. J Plant Res 126:567-576

Guidi L, Calatayud A (2014) Non-invasive tools to estimate stressinduced changes in photosynthetic performance in plants inhabiting Mediterranean areas. Environ Exp Bot 103:42-52

Hagaggi NSA, Mohamed AAA (2020) Enhancement of Zea mays (L.) growth performance using indole acetic acid producing endophyte Mixtatheicola isolated from Solenostemma argel (Hayne). S Afr J Bot. https://doi.org/10.1016/j.sajb.2020.02.034

Ikbal F, Hernández JA, Barba-Espín G, Koussa T, Aziz A, Faize M, Diaz-Vivancos P (2014) Enhanced salt-induced antioxidative responses involve a contribution of polyamine biosynthesis in grapevine plants. J Plant Physiol 171:779-788

Ilangumaran G, Smith DL (2017) Plant growth promoting rhizobacteria in amelioration of salinity stress: a systems biology perspective. Front Plant Sci 8:1768

ISTAT (2018) <http://www.istat.it/en/> Accessed Mar 2016

Jia Y, Yang X, Islam E (2008) Effects of potassium deficiency on chloroplast ultra-structure and chlorophyll fluorescence in inefficient and efficient genotypes of rice. J Plant Nutr 31(12):2105-2118

Kamran M, Parveen A, Ahmar S, Malik Z, Hussain S, Chattha MS, Saleem MH, Adil M, Heidari P, Chen JT (2020) An overview of hazardous impacts of soil salinity in crops, tolerance mechanisms, and amelioration through selenium supplementation. Int $\mathbf{J}$ Mol Sci 21:148

Kanagendran A, Chatterjee P, Liu B, Sa T, Pazouki L, Niinemets U (2019) Foliage inoculation by Burkholderia vietnamiensis CBMB40 antagonizes methyl jasmonate-mediated stress in Eucalyptus grandis. J Plant Physiol 242:153032

Kramer DM, Johnson G, Kiirats O, Edwards GE (2004) New fluorescence parameters for the determination of QA redox state and excitation energy fluxes. Photosynth Res 79:209-218

Kumar A, Patel AS, Meena VS, Srivastava R (2019) Recent advances of PGPR based approaches for stress tolerance in plants for sustainable agriculture. Biocatal Agric Biotechnol 20:101271. https:// doi.org/10.1016/j.bcab.2019.101271

Li YL, Jin ZX, Guan M (2013) Effects of soil microbes on photosynthetic characteristics and chlorophyll fluorescence parameters of elsholtzia splendens under copper stress condition. Bull Bot Res 33(6):684-689

Liu C, Liu Y, Lu Y, Liao Y, Nie J, Yuan X, Chen F (2019) Use of a leaf chlorophyll content index to improve the prediction of aboveground biomass and productivity. PeerJ 6:e6240. https://doi.org/ 10.7717/peerj.6240

Malinská H, Pidlisnyuk V, Nebeská D, Erol A, Medžová A, Trögl J (2020) Physiological response of Miscanthus x giganteus to plant growth regulators in nutritionally poor soil. Plants 9:194

Maxwell K, Johnson GN (2000) Chlorophyll fluorescence-a practical guide. J Exp Bot 51:659-668

Meena VS, Meena SK, Verma JP, Kumar A, Aeron A, Mishra PK, Bisht JK, Pattanayak A, Naveed M, Dotaniya ML (2017) Plant beneficial rhizospheric microorganism (PBRM) strategies to improve nutrients use efficiency: a review. Ecol Eng 107:8-32

Nautiyal CS, Srivastava S, Chauhan PS, Seem K, Mishra A, Sopory SK (2013) Plant growth-promoting bacteria Bacillus amyloliquefaciens NBRISN13 modulates gene expression profile of leaf and rhizosphere community in rice during salt stress. Plant Physiol Biochem 66:1-9

Navarro A, Bañón S, Conejero W, Sánchez-Blanco MJ (2008) Ornamental characters, ion accumulation and water status in Arbutus unedo seedlings irrigated with saline water and subsequent relief and transplanting. Environ Exp Bot 62:364-370

NowickaB CJ, Szymańska R, Kruk J (2018) Improving photosynthesis, plant productivity and abiotic stress tolerance — current trends and future perspectives. J Plant Physiol 231:415-433

Paulsen GM, Shroyer JP, Shroyer KJ (2016) Wheat: agronomy. Encycl Food Grains 4:176-185. https://doi.org/10.1016/B978-0-12394437-5.00200-X

Pii Y, Mimmo T, Tomasi N, Terzano R, Cesco S, Crecchio C (2015) Microbial interactions in the rhizosphere: beneficial influences of plant growth promoting Rhizobacteria on nutrient acquisition process. A Review. Biol Fertil Soils 51:403-415

Pii Y, Borruso L, Brusetti L, Crecchio C, Cesco S, Mimmo T (2016) The interaction between iron nutrition, plant species and soil type shapes the rhizosphere microbiome. Plant Physiol Biochem 99:39-48

Porra RJ (2002) The chequered history of the development and use of simultaneous equations for the accurate determination of chlorophylls a and b. Photosynth Res 73:149-156

Prasad R (2010) Zinc biofortification of food grains in relation to food security and alleviation of zinc malnutrition. Curr Sci 98:1300-1304

Rengel Z (2015) Availability of Mn, Zn and Fe in the rhizosphere. J Soil Sci Plant Nutr 15(2):397-409

Roháček K (2002) Chlorophyll fluorescence parameters: the definitions, photosynthetic meaning, and mutual relationships. Photosynthetica 40(1):13-29 
Salvatori E, Fusaro L, Gottardini E, Pollastrini M, Goltsev V, Strasser RJ, Bussotti F (2014) Plant stress analysis: application of prompt, delayed chlorophyll fluorescence and $820 \mathrm{~nm}$ modulated reflectance. Insights from independent experiments. Plant Physiol Biochem 85:105-113

Salvatori E, Fusaro L, Manes F (2017) Effects of the antiozonant ethylenediurea (EDU) on Fraxinus ornus L.: the role ofdrought. Forests 8(9):320, 2017.

Santiago CD, Yagi S, Ijima M, Nashimoto T, Sawada M, Ikeda S, Asano K, Orikasa Y, Ohwada T (2017) Bacterial compatibility in combined inoculations enhances the growth of potato seedlings. Microbes Environ 32(1):14-23

Sayyad-Amin P, Jahansooz MR, Borzouei A, Ajilli F (2016) Changes in photosynthetic pigments and chlorophyll- $a$ fluorescence attributes of sweet-forage and grain sorghum cultivars under salt stress. J Biol Phys 42:601-620

Shah SH, Houborg R, McCabe MF (2017) Response of chlorophyll, carotenoid and SPAD-502 measurement to salinity and nutrient stress in wheat (Triticum aestivum L.). Agronomy 7(3):1-21

Shu S, Yuan LY, Guo SR, Sun J, Yuan YH (2013) Effects of exogenous spermine on chlorophyll fluorescence, antioxidant system and ultra structure of chloroplasts in Cucumis sativus L. under salt stress. Plant Physiol Biochem 63:209-216

Vandana UK, Singha B, Gulzar ABM, Mazumder PB (2020) Molecular mechanisms in plant growth promoting bacteria (PGPR) to resist environmental stress in plants. Academic Press, Cambridge, pp 221-233. https://doi.org/10.1016/B978-0-12-818469-1.00019-5

Wang X, Wang L, Shangguan Z (2016) Leaf gas exchange and fluorescence of two winter wheat varieties in response to drought stress and nitrogen supply. PLoS ONE 11(11):e0165733

Yaghoubi Khanghahi M, Ricciuti P, Allegretta I, Terzano R, Crecchio C (2018a) Solubilization of insoluble zinc compounds by zinc solubilizing bacteria (ZSB) and optimization of their growth conditions. Environ Sci Pollut R 25:25862-25868

Yaghoubi Khanghahi M, Pirdashti H, Rahimian H, Nematzadeh GA, Ghajar Sepanlou M (2018b) Potassium solubilising bacteria
(KSB) isolated from rice paddy soil: from isolation, identification to K use efficiency. Symbiosis 76:13-23

Yaghoubi Khanghahi M, Pirdashti H, Rahimian H, Nematzadeh GA, Ghajar Sepanlou M (2018c) Nutrient use efficiency and nutrient uptake promoting of rice by potassium solubilizing bacteria (KSB). Cereal Res Commun 46(4):739-750. https://doi.org/10. 1556/0806.46.2018.042

Yaghoubi Khanghahi M, Pirdashti H, Rahimian H, Nematzadeh GA, Ghajar Sepanlou M, Salvatori E, Crecchio C (2019a) Evaluation of leaf photosynthetic characteristics and photosystem II photochemistry of rice (Oryza sativa L.) under potassium soloubilizing bacteria (KSB) inoculation. Photosynthetica 57(2):500-511

Yaghoubi Khanghahi M, Pirdashti H, Rahimian H, Nematzadeh GA, Ghajar Sepanlou M (2019b) The role of potassium solubilizing bacteria (KSB) inoculations on grain yield, dry matter remobilization and translocation in rice (Oryza sativa L.). J Plant Nutr 42(10):1165-1179

Yaghoubi Khanghahi M, Strafella S, Allegretta E, Crecchio C (2020) Isolation of bacteria with potential plant-promoting traits and optimization of their growth conditions. Curr Microbiol. https://doi. org/10.1007/s00284-020-02303-w

Yaghoubian Y, Siadat SA, Moradi Taelavat MR (2016) Quantify the response of purslane plant growth, photosynthesis pigments and photosystem II photochemistry to cadmium concentration gradients in the soil. Russ J Plant Physiol 63(1):77-84

Yong JWH, Ng YF, Tan SN, Chew AYL (2010) Effect of fertilizer application on photosynthesis and oil yield of jatropha curcas $\mathrm{L}$. Photosynthetica 48:208-218

Zulkarami B, Tajul MI, Fariz A, Husni MO, Norazrin A, Radziah O, Rafii MY (2012) Effects of bacteria and arbuscular mycorrhizae inoculation at different electrical conductivity level on growth and yield of rockmelon (Cucumis melo) under soilless culture. Aust J Crop Sci 6:1494-1501

Publisher's Note Springer Nature remains neutral with regard to jurisdictional claims in published maps and institutional affiliations. 